\title{
Bietti' Crystalline Retinal Dystrophy: A Case Report
}

\author{
Muhammed Şahin, Adnan Yıldırım, Fatih Mehmet Türkcü, Harun Yüksel, Alparslan Şahin
}

\begin{abstract}
Bietti' crystalline retinal dystrophy $(B C D)$ is a rare, autosomal, recessively inherited disorder, characterized by the deposition of yellow crystals in the corneal limbus and retina. In this paper we aimed to present a pediatric case with $B C D$, with clinical, electrophysiological and spectral domain optical coherence tomography (SD-OCT) findings and discuss BCD with the light of the literature. J Clin Exp Invest 2016; 7 (1): 94-97
\end{abstract}

Key words: Bietti' crystalline dystrophy, cornea, crystalline deposits, retina

\section{Bietti’ Kristalin Retinal Distrofi: Olgu Sunumu}

\section{ÖZET}

Bietti kristalin retina distrofisi (BCD) korneal limbus ve retinada sarı renkli kristallerin birikmesi ile karakterize, nadir görülen, otozomal resesif kalıtsal bir hastalıktır. Bu yazıda, klinik, elektrofizyolojik ve spektral domain optik koherens tomografi (SD-OKT) bulguları ile BCD' li pediatrik bir olgu sunmayı ve literatür eşliğinde BCD'yi tartışmayı amaçladık.

Anahtar kelimeler: Bietti kristalin retina distrofi, kornea, kristalin depozit, retina.

\section{INTRODUCTION}

Bietti' crystalline retinal dystrophy $(\mathrm{BCD})$ is a rare, autosomal, recessively inherited disorder, characterized by the deposition of yellow crystals in the corneal limbus and retina. Loss of vision occurs due to retinal and choroidal atrophy [1]. It can be asymptomatic and incidentally diagnosed in an ordinary ocular examination. BCD is more common in East Asia especially in China and Japan, and it accounts for 3\% of all nonsyndromic retinitis pigmentosa (RP) and $10 \%$ of all autosomal recessive $\mathrm{RP}$ patients $[2,3]$.

In this paper we aimed to present a pediatric case with $\mathrm{BCD}$, and discuss $\mathrm{BCD}$ with the light of the literature.

\section{CASE REPORT}

A 10-years-old boy presented to our clinic with gradual loss of vision one last years. On initial examination, his Snellen's visual acuity was 0.1 bilaterally. On slit-lamp biomicroscopy, a few glistening crystalline deposits were visible bilaterally in the limbal cornea. Fundus examination revealed bilateral diffuse retinal crystalline deposits, atrophy of the neural retina, retinal pigment epithelium, and choriocapillaris (Figure $1)$.

In the family history of the patients there were no people who suffered from any ocular disease. However, all family members were undergone an ocular examination. The mother of our case had crystalline retinopathy however here vision acuity was not decreased. Beside big brother of our case reduced ERG responses with normal fundus. In our case there were no history of any drug usage or systemic disease.

The scotopic, photopic, and maximal combined responses were slightly reduced and the $30-\mathrm{Hz}$ flicker response was also mildly reduced on full-field electroretinography (ERG) (Figure 2). Visual Evoked potentials (VEP) revealed subnormal responses (Figure 3). Electrooculography was within normal range.

Spectral domain optical coherence tomography (SD-OCT) (Spectralis; Heidelberg Engineering, Heidelberg, Germany) showing the atrophy of choriocapillaris and hyper-reflective plaque at the level of RPEBruch's membrane correspond to crystalline deposits (Figure 4).

Dicle University, School of Medicine, Department of Ophthalmology, Diyarbakır, 21280, Turkey

Correspondence: Muhammed Şahin,

Dicle University School of Medicine Department of Ophthalmology Diyarbakır, Turkey Email: drmuhammedsahin@gmail.com Received: 09.12.2015, Accepted: 17.02.2016

Copyright @ JCEI / Journal of Clinical and Experimental Investigations 2016, All rights reserved 

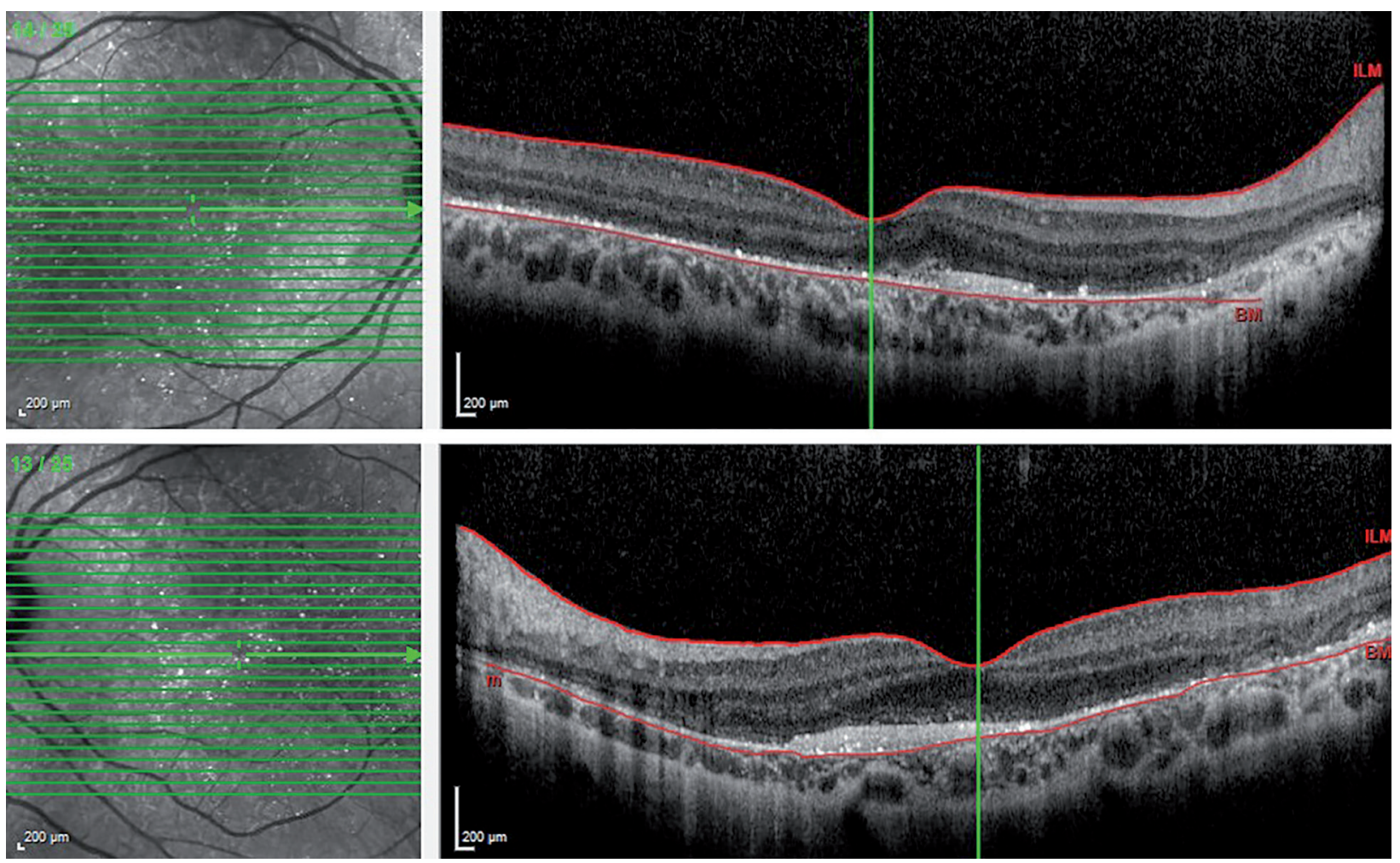

Figure 1. Bilateral color fundus photos revealing intraretinal sparkling yellow crystals distributed in the posterior pole.

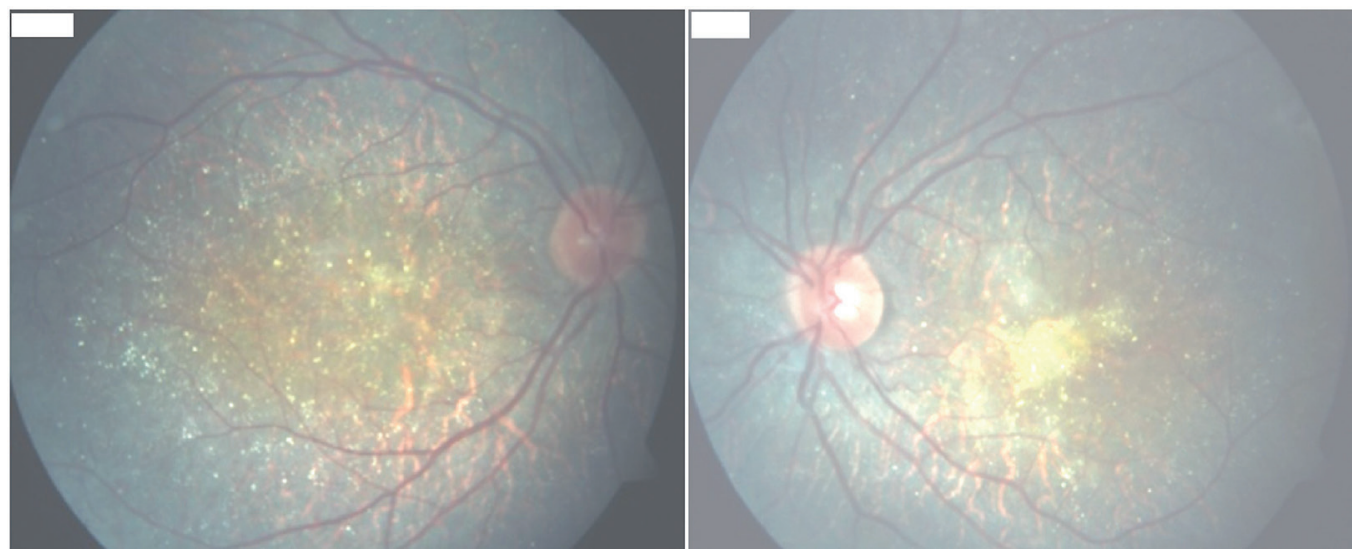

Figure 2. The Electroretinography showed decreased scotopic a and b-waves amplitudes and the photopic a and b waves, $30 \mathrm{~Hz}$ flicker amplitudes were subnormal.


Figure 3. Visual evoked potential test revealing subnormal responses. 

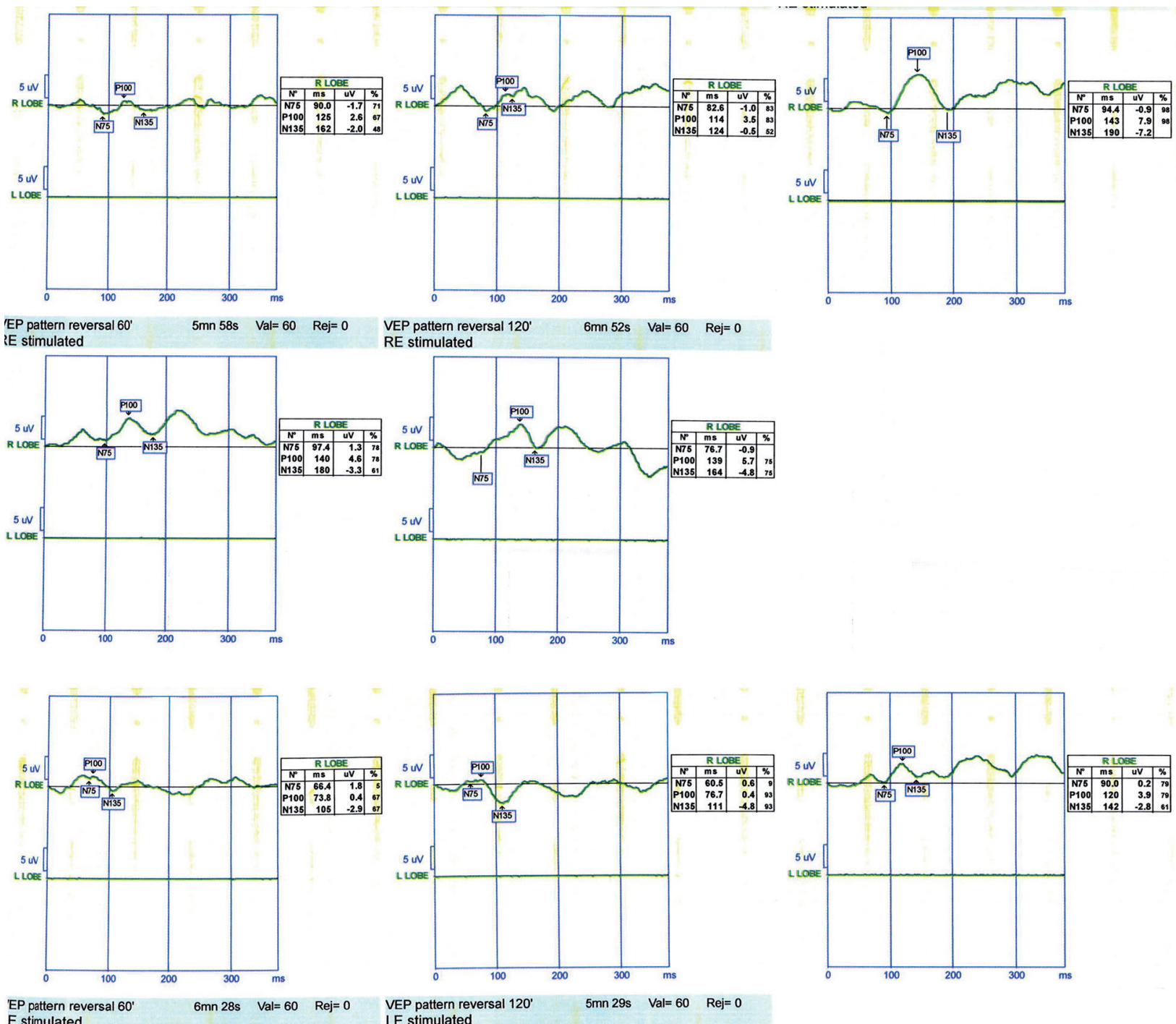

E stimulated
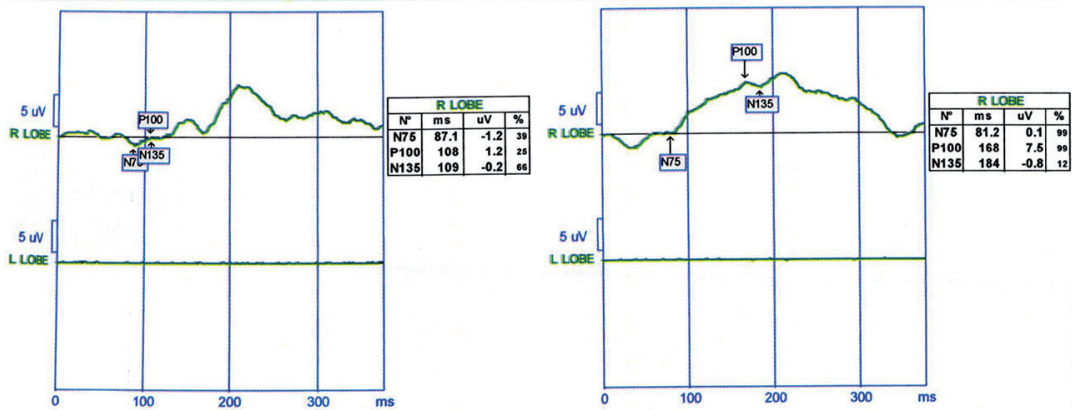

Figure 4. Hyperreflective plaque at the level of RPE-Bruch's membrane and choriocapillaris complex correspond to crystalline deposits were seen on OCT.

\section{DISCUSSION}

Bietti' crystalline retinal dystrophy is an uncommon, inherited, retinal degeneration associated with retinal crystal deposits and gradual vision loss. The biochemical composition of the crystals in the eyes with BCD has not been determined exactly. Electron microscopy (EM) confirmed the presence of crystalline materials in the circulating lymphocytes and the skin fibroblasts in patients with $\mathrm{BCD}$ [4].

Bietti' crystalline dystrophy typically presents between the second and fourth decades of the life as our 
case with progressive night blindness, progressive vision loss, and visual field constriction, often with legal blindness in the fifth or sixth decades of life [5].

It is caused by CYP4V2 gene mutation [6]. A mutated CYP4V2 gene results in photoreceptor loss secondary to the degeneration of the RPE due to intracellular retinal pigment epithelial crystalline deposits, and abnormal lipid metabolism.

The results of several SD-OCT studies suggested that the crystals were mainly located adjacent to the RPE layer [7-9]. However, that crystal deposits were seen in all the different retinal layers in SD-OCT studies $[9,10]$. Another study demonstrated that retinal crystals were observed as tiny hyperreflective lesions localized in the choroid [11].

In addition, the characteristic structure most frequently noted in the SD-OCT image was a sphericalshaped hyperreflective lesion. Additionally reported structures were described as a 'tube formation' or 'rosette formation [9]. In our patient, there are a spherical-shaped hyper-reflective lesion and hyperreflective crystal deposits at the level of RPE-Bruch's membrane and choriocapillaris complex (Figure 4). However, tube formation or rosette formation was not seen probably due to the younger age of our patient.

ERG findings of the BCD patients were mostly subnormal and consistent with the dysfunction of the cones and rods. ERG usually reveals reduced amplitudes in scotopic, photopic and $30 \mathrm{~Hz}$ flicker responses [1]. Previous studies report full-field ERGs ranging from normal to undetectable, with most having generalized rod and cone system involvement [12]. The ERG response of our case was reduced. It was previously suggested that ERG is a sensitive indicator of disease progression [13]. Nevertheless, normal ERG amplitude and latency have recently been detected in BCD patients with decreasing visual acuity and night blindness [14]. Therefore, ERG in BCD might not be closely related with disease progression.

In some cases as an early sign, ERG responses reduces before occurrence of vision loss like in mother an big brother of our case. Additionally hyperreflective dots might be seen in SD-OCT. The combined use of these two devices is important in diagnosis and follow up [12].

In conclusion $\mathrm{BCD}$ is an autosomal recessive inherited progressive retinal disorder that threatens vision. In this paper we presented a rare case of BCD and discuss with previously published literature. Ge- netic counseling and low vision aids may be helpful in BCD patients with low visual acuity. OCT is useful tool in the diagnosis of BCD and it demonstrates the localization of the deposits.

Declaration of Conflicting Interests: The authors declare that they have no conflict of interest.

Financial Disclosure: No financial support was received.

\section{REFERENCES}

1. Wilson DJ, Weleber RG, Klein ML, et al. Bietti's crystalline dystrophy: A clinicopathologic correlative study. Arch. Ophthalmol 1989;107:213-221.

2. Mataftsi A, Zografos L, Millá E, et al. Bietti’s crystalline corneoretinal dystrophy: a cross-sectional study. Retina Phila. Pa 2004;24:416-426.

3. Hu DN. Prevalence and mode of inheritance of major genetic eye diseases in China. J. Med. Genet 1987;24:584-588.

4. Kaiser-Kupfer MI, Chan CC, Markello TC, et al. Clinical biochemical and pathologic correlations in Bietti's crystalline dystrophy. Am. J. Ophthalmol 1994;118:569-582.

5. Okialda KA, Stover NB, Weleber RG, Kelly EJ. Bietti Crystalline Dystrophy. 2012 [cited 2015 Oct 13]; Available from: http://www.ncbi.nlm.nih.gov/books/NBK91457/

6. Li A, Jiao X, Munier FL, et al. Bietti Crystalline Corneoretinal Dystrophy Is Caused by Mutations in the Novel Gene CYP4V2. Am. J. Hum. Genet 2004;74:817-826.

7. Gocho K, Kameya S, Akeo K, et al. High-Resolution Imaging of Patients with Bietti Crystalline Dystrophy with CYP4V2 Mutation. J. Ophthalmol 2014;2014:283603.

8. Pennesi ME, Weleber RG. High-resolution optical coherence tomography shows new aspects of Bietti crystalline retinopathy. Retina Phila. Pa 2010;30:531-532.

9. Kojima H, Otani A, Ogino K, et al. Outer retinal circular structures in patients with Bietti crystalline retinopathy. Br J. Ophthalmol 2012;96:390-393.

10. Querques G, Quijano C, Bouzitou-Mfoumou R, et al. In-Vivo Visualization of Retinal Crystals in Bietti's Crystalline Dystrophy by Spectral Domain Optical Coherence Tomography. Ophthalmic Surg. Lasers Imaging Off. J. Int. Soc. Imaging Eye 2010;1-3.

11. Zerbib J, Ores R, Querques G, et al. Choroidal findings in Bietti's crystalline dystrophy. Retin Cases Brief Rep 2014;8:130-131.

12. Halford S, Liew G, Mackay DS, et al. Detailed Phenotypic and Genotypic Characterization of Bietti Crystalline Dystrophy. Ophthalmology 2014;121:1174-1184.

13. Lee KYC, Koh AHC, Aung T, et al. Characterization of Bietti crystalline dystrophy patients with CYP4V2 mutations. Invest Ophthalmol Vis. Sci 2005;46:3812-3816.

14. Rossi S, Testa F, Li A, et al. An atypical form of Bietti crystalline dystrophy. Ophthalmic Genet 2011;32:118-121. 